\title{
Architectural Analysis of Photovoltaic Systems Subjected to Partial Shading with a Simple DC-DC Step-up Converter
}

\author{
Santhoshi Snigdha Buddala, Vijay Devabhaktuni \\ Department of Electrical Engineering \& Computer Science \\ The University of Toledo \\ Toledo, $\mathrm{OH} 43606$, USA \\ santhoshis.buddala@rockets.utoledo.edu
}

\author{
Srinivasa Vemuru \\ Department of Electrical and Computer Engineering \\ Ohio Northern University \\ Ada, $\mathrm{OH} 45810$, USA \\ s-vemuru@,onu.edu
}

\begin{abstract}
The output voltage of parallel connected solar cells is very low to drive the load connected across its terminals even though they are efficient in delivering the peak output power even under extreme partial shading conditions. A basic dc-de boost converter circuit is used in this paper to evaluate the performance of a parallel architecture in comparison with series and series-parallel architectures. SPICE simulations are used to analyze the architectures and identify the best configuration in terms of power conversion efficiency under different partial shading scenarios as well as in normal operation.
\end{abstract}

\section{INTRODUCTION}

The growing interest towards the use of renewable energy sources is sustained by the continuing research that enhances improvement of existing conversion technologies and development of new systems [1], [2], [3]. Photovoltaic (PV) cells are specialized semiconductors that generate electrical current when irradiated with light; thus converting the solar energy to electrical energy by a phenomenon named photovoltaic effect. PV modules are made of PV cells connected in series and parallel configurations to generate higher voltages and currents. The manufacturing, material and architectural constraints limit the number of cells that can be combined in these configurations. Therefore, PV modules are interconnected to form PV arrays. These PV arrays can be implemented in a stand-alone or to the grid connected power systems. The application of PV systems in a small scale (less than $5 \mathrm{~kW}$ ) residential stand-alone configuration as an essential electricity source is more often used than the grid connected configurations [4]. This paper presents the impact of partial shading on the performance of a PV array power generation. A simple dc-dc converter circuit is interconnected with different photovoltaic topologies to boost up the output voltage. Three different PV topologies are discussed in terms of power efficiencies when subjected to partial shading.

The performance of the solar panel depends on temperature, irradiance of the sun, topology of solar array, and shading across the panel. Shading due to reduced irradiance during sunset and night times, photovoltaic aging, etc., have almost uniform impact on power generation across the solar panel. However, phenomena such as dust deposition on the panel, passing clouds, shade of the trees or adjacent buildings, bird droppings, etc., lead to partial shading condition wherein the PV panel cannot deliver the specified power. The effect of this is not only the loss in output power but also the power loss is within the panel. This is because the shaded cells operate in the reverse bias state draining away the power generated from the illuminated cells. This leads to further temperature increase and local heating; this creates thermal stress on the solar panel resulting in hot spot formation [5].

In residential installations, the major affect is due to partial shading from shadow cast by adjacent buildings, chimney tops, big trees, etc. Most of the commonly used PV arrays have cells connected in series to reach specific output voltage. Figure 1 shows an array of cells in series under partial shading condition. Partial shading causes a significant drop in the output power of the solar array because the current through the series-connected string in modules is affected by the shaded cell [6]. This degrades the photovoltaic array performance. Employing bypass diodes can reduce these losses. PV arrays with cells in parallel, as shown in Figure 2, can mitigate the partial shading effect and generate close to peak output power that occurs at a fixed load resistance value irrespective of the number of cells shaded [7].

But the predominant limitation of a parallel array is that the output voltage is too low for the connected load. Therefore, the parallel architecture is overlooked by the researchers over years. This study looks into the effects of using a suitable dcdc power converter that can boost up the output voltage of the parallel array to suitable level and take advantage of the resilience of the parallel arrays under partial shading. In Section II, the impact of power converter on the solar array performance is described. In Section III, three different configurations of solar arrays are presented. Section IV discusses the performance of PV systems followed by conclusions in Section V.

This work was supported in part by the National Science

Foundation under awards 0958355 and 1000744. 


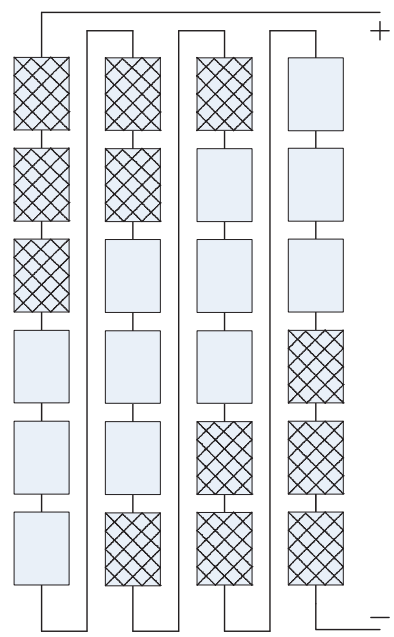

Fig. 1 Series connected PV array subjected to partial shading condition

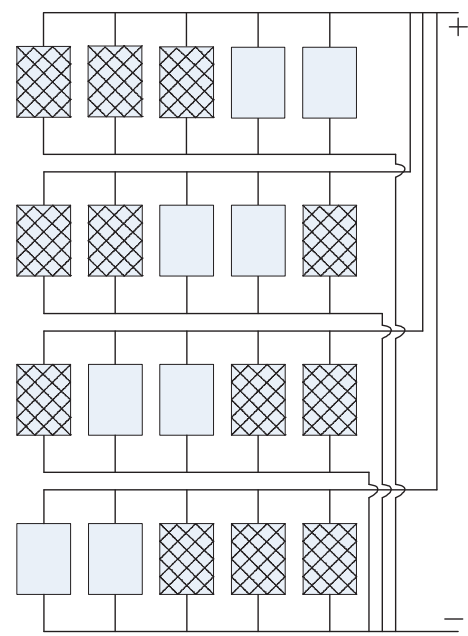

Fig. 2 Parallel connected PV array subjected to partial shading condition

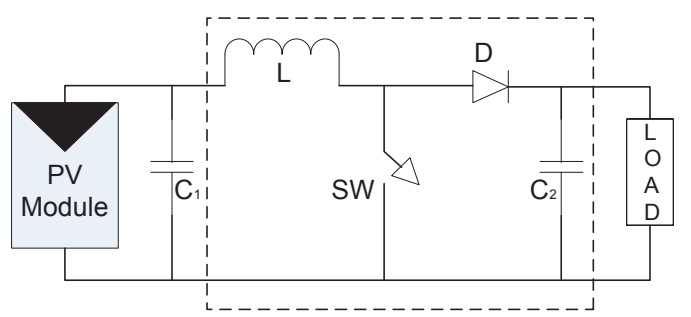

Fig. 3 A simple DC-DC converter integrated with PV module

\section{INTEGRATION OF DC-DC CONVERTER}

Figure 3 shows a simple dc-dc boost converter that steps up the input voltage to a higher level at the output end. The operation of the converter depends on the current flow through the inductor, $L$, with the switch, $S W$, being periodically turned on and off. The diode, $D$ acts as a blocking diode to prevent the discharge of the capacitor through the switch and also provides a path for the current flow through the output load when the switch is turned off. An output capacitor, $C_{2}$, connected across the load acts as a filter in reducing the voltage ripples.
Capacitor $C_{l}$ is placed at the output of the PV panel to avoid the high frequency ohmic losses caused by the ripple transients of the inductor which may flow back into the panel.

The analysis in this paper is based on the assumptions that the converter is always operating in continuous conduction mode (CCM), and the inductor current is always positive.

There are two cases in the analysis with the switch being closed and with the switch being opened. When the switch is closed, $\left[C_{I^{-}}-\mathrm{L}-\mathrm{SW}\right]$ forms a closed path where the inductor voltage matches the output of the PV module. When the switch is opened, the inductor, with an inherent property of opposing the sudden current transients, acts as an added source to the load along with the PV panel. In this case, $\left[C_{1}-L-\right.$ $\left.D-C_{2}\right]$ acts as a closed path in delivering the power to the load. The voltage increase of a boost converter is given as:

$$
V_{o}=\frac{V_{i}}{1-D}
$$

where $\mathrm{V}_{\mathrm{o}}$ is the output voltage of the Boost converter, $\mathrm{V}_{\mathrm{i}}$ is the input voltage to the converter, and $\mathrm{D}$ is the duty cycle of the switch operation that can be between 0 to 1 .

If the switch is always open and D is zero, the output voltage equals the input voltage. As the duty ratio increases, the denominator becomes smaller, and the output becomes larger than the input. When the duty ratio of the switch approaches unity the output goes to infinity; however, it is not practically possible because of the real components used in the converter design which have added internal resistance [8].

\section{COMPARISON OF ARRAY ARCHITECTURES}

The comparison of three different topologies 1) Series configuration, 2) Parallel configuration and 3) Series-Parallel configuration along with the dc-dc converter under varying partial shading conditions is carried out in SPICE. A comparative study of the results in each of the three cases is discussed.

\section{A. Series vs Parallel Configuration}

Figure 4 shows a string of series connected cells attached to a resistive load through a dc-dc converter. Similarly, Figure 5 represents a parallel PV system where the cells are connected in parallel across the converter and load. The cells that are shaded are represented with a cross. In the simulation study, both the architectures have equal number of cells. Sixty cells in each of the series and parallel model are considered with 20 cells shaded at different irradiance levels. The two architectures, representing the two possible extremes of interconnections between the cells, are simulated in SPICE and the results are presented in Table 1.

In the first column of Table 1 , the percentage variation in irradiance on shaded cells from full illumination at $0 \%$ to no illumination at $100 \%$ shading is given. The output voltage, output power, and efficiency of boost converter are compared in the next six columns for the two architectures. It is observed that power efficiency for the series architecture in sub-column 3 of column 2 reduces from $94 \%$ to $0 \%$ as shading on cells increased. Under extreme partial shading conditions, the 
output voltage and power generated by PV arrays become extremely small as shown in sub-columns 2 and 3 of Table I. Series architecture holds well up to $80 \%$ of shading on cells but beyond that there is a drastic fall in the output power. This is due to the fact that in normal mode of operation all the cells operate in forward bias mode carrying same current and generating small positive voltages. When one or more cells in the string are partially or fully shaded they tend to operate in reverse biased mode generating a significantly large reverse or negative voltage. This negative voltage offsets the positive voltage generated by the unshaded cells resulting in very small output voltage. This results in a significant power loss in the shaded cell within the series string [7]. This decrease in the output voltage of the series architecture causes a reduction to the input voltage to the power converter. Low input voltages to the Boost power converter results in low conversion efficiencies. Thus under partial shading scenario beyond $80 \%$ the output power starts to reduce precipitously in series architectures.

In the case of parallel PV architectures as shown in Figure 5 , even under extreme partial shading conditions of $90-100 \%$, the PV generation systems has a fairly constant low conversion efficiency of about $36 \%$ as shown in sub-column 3 of column 3. A highly paralleled architecture delivers power at a very low voltage and high currents. These large currents result in high conduction and switching losses even for a reasonably low internal resistance of the converter; thus, there is a very large relative voltage drop which results in reduced power conversion efficiency. Therefore under low to moderate shading conditions, the parallel architecture has low output power and voltage as shown in Table 1. Thus a solar array in parallel configuration has performance superior to series architecture at increased partial shading conditions and inferior performance under normal to low partial shading conditions. Most of shading scenarios such as shadows, bird droppings, etc., result in high partial shading and parallel architecture may give better performance in those conditions. However, excessively high currents flow through parallel cells as compared to the series connection; larger currents result in higher $\mathrm{I}^{2} \mathrm{R}$ losses.

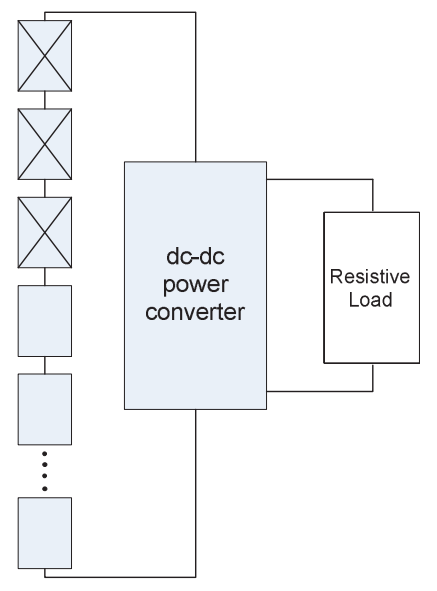

Fig. 4 Block diagram of a series architecture subjected to partial shading condition
TABLE I. COMPARISON OF OUTPUT POWER AND EFFICIENCIES IN SERIES AND PARALLEL ARCHITECTURES

\begin{tabular}{|c|c|c|c|c|c|c|}
\hline \multirow{2}{*}{$\begin{array}{c}\text { Shade } \\
(\%)\end{array}$} & \multicolumn{3}{|c|}{ Series Architecture } & \multicolumn{3}{c|}{ Parallel Architecture } \\
\cline { 2 - 7 } & Vo (V) & Po (W) & Eff (\%) & Vo (V) & Po (W) & Eff (\%) \\
\hline 0 & 20.69 & 8.56 & 93.76 & 1.389 & 1.93 & 36.39 \\
\hline 20 & 20.62 & 8.5 & 93.72 & 1.379 & 1.85 & 35.79 \\
\hline 40 & 20.51 & 8.4 & 93.85 & 1.369 & 1.90 & 36.19 \\
\hline 60 & 20.32 & 8.26 & 94.40 & 1.371 & 1.88 & 36.12 \\
\hline 80 & 19.85 & 7.8 & 94.00 & 1.351 & 1.827 & 36.1 \\
\hline 100 & 0 & 0 & 0 & 1.252 & 1.568 & 35.75 \\
\hline
\end{tabular}

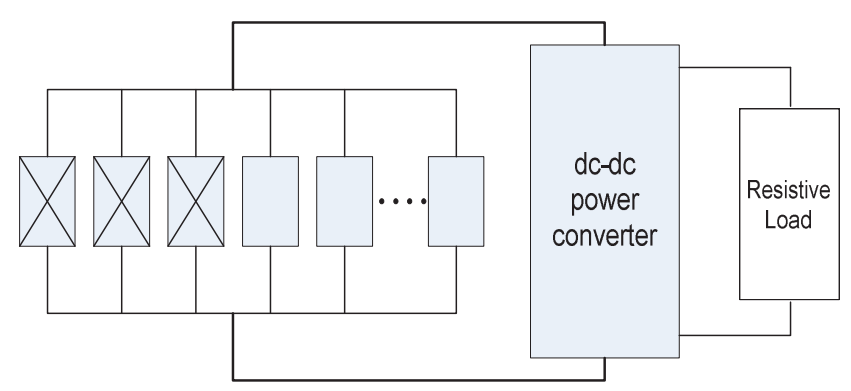

Fig. 5 Block diagram of a parallel architecture subjected to partial shading condition

\section{B. Series- Parallel Configuration}

Pure series architecture provides good power conversion efficiency but presents reliability concerns under extreme shading conditions. On the other hand, parallel connected solar architectures provide a stable power conversion efficiency which is very low. These two architectures cannot provide consistent power conversion efficiency. Therefore combining both of these features, a series-parallel configuration is used as shown in Figure 6. The cells that are shaded are represented with a cross mark. Sixty cells are interconnected as in the prior simulations, with 6 cells in each series string connected in 10 parallel columns. The series-parallel architecture is then connected to a resistive load through a Boost converter and the SPICE simulation results are tabulated in Table II.

Twenty cells are shaded at different irradiance levels from full irradiance to no irradiance as shown in column 1 of Table II. The shading patterns are selected as row-wise with 20 shaded cells located horizontally, and column-wise with 20 cells shaded in vertical columns. In case of row-wise shading, as the percentage of shading increases, the output voltage and power decreases as shown in sub-columns 1 and 2 of column 2. When the shading percentage increases beyond $80 \%$, it renders the entire column ineffective and the performance becomes similar to series-connected strings. The shaded cells in the series string produce reverse voltages and start consuming power than generating to the load. The output power efficiency reduces significantly for the series string as shown in sub-column 3 of column 2 due to lower input voltages given to the dc-dc converter. 


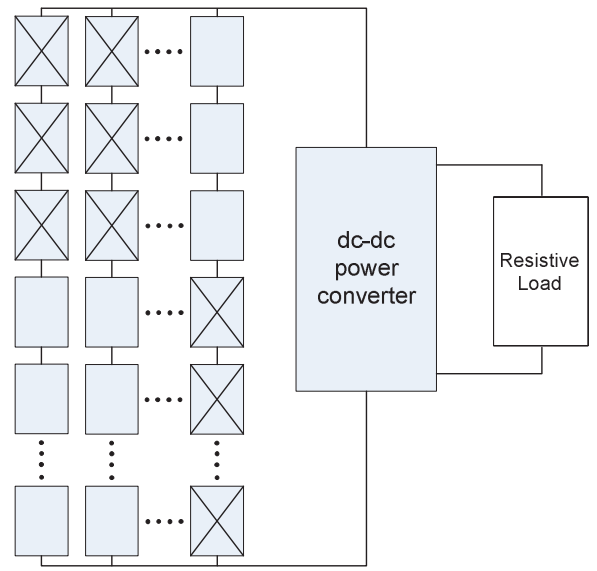

Fig. 6 Block diagram of a series-parallel (6x10) architecture subjected to partial shading condition

This effect is not as pronounced in the case of column wise shading because the current required by the shaded cells is contributed by the illuminated cells in parallel strings. Even under worst partial shading condition, there is significant power delivered to the output load.

\section{PERFormance ANALYSIS OF SERIES-PARALlEL ARCHITECTURE}

From the above discussion, it is observed that the overall performance of a series-parallel architecture is consistent under normal as well as partial shading condition. Table III summarizes the data points of different configurations of 60 cells at maximum illumination. Column 1 represents the organization of the 60 cells. Column 2 and 3 show the input voltage generated to the $\mathrm{dc}-\mathrm{dc}$ converter and the resulting power efficiency. It is observed from the data that as the input voltage increases the efficiencies are increasing. Thus the $60 \times 1$ series module with an input voltage of $16.31 \mathrm{~V}$ has the highest efficiency of $93.46 \%$ and the $1 \times 60$ parallel module with $0.472 \mathrm{~V}$ has the least efficiency of $36.39 \%$. The performances of the remaining intermediate structures between the two extreme cases have better power conversion efficiencies even under extreme partial shading conditions.

Figure 7 shows the variation in power efficiencies for different architectures discussed in Table III with respect to input voltages and number of cells connected in series. Since S-P (series-parallel) architecture has reasonable power efficiency and is more tolerant to partial shade, we extend the model and validate the results of a $6 \times 10$ sample panel with 60 cells used in the prior analysis with increased number of cells.

Figure 8 shows the increase in the power efficiency of a series-parallel configuration with an increase in number of cells. It clearly shows that with increase in the number of cells connected in series for a given solar array configuration, the power efficiency reaches the maximum efficiency of series architecture. The trend line joining all of the data points is given as:

$$
E=14.703 * \ln (x)+36.336
$$

where $E$ is the power efficiency (expressed in \%) and $x$ is the number of series connected solar cells.

The conversion efficiency of a Boost converter improves with number of series-connected cells. However, the efficiency of the series architectures when extended to a larger array of solar cells is not expected to significantly increase from $94 \%$ as the efficiency saturates out. On the other hand, in case of a series-parallel architecture, the larger arrays provide further increase to the input voltage provided to the dc-dc converter. Therefore, it is possible to improve the efficiency from $70 \%$ to a value approaching the efficiencies of the series architecture. This combined with better operation of seriesparallel architecture under extreme partial shading conditions makes the architecture more suitable for large arrays to improve the reliability and lifetime of the solar arrays.

For example, if eqn (2) is extrapolated to a series-parallel architecture comprising of 1000 cells, with 50 cells in series, connected in 20 parallel columns, the increased input voltage based from eqn 2 results in an increase of power efficiency to $93.85 \%$. Therefore, 50x20S-P architecture has efficiency almost equal to the series architecture while being more tolerant to partial shading.

TABLE II. SPICE SIMULATION RESULTS OF A SERIES-PARALLEL ARCHITECTURE With COLUMN-WiSE AND ROW-WiSE SHADING

\begin{tabular}{|c|c|c|c|c|c|c|}
\hline \multirow{2}{*}{$\begin{array}{c}\text { Shade } \\
(\%)\end{array}$} & \multicolumn{3}{|c|}{$\begin{array}{c}\text { S-P Array } \\
\text { (Row wise Shading) }\end{array}$} & \multicolumn{3}{c|}{$\begin{array}{c}\text { S-P Array } \\
\text { (Column wise shading) }\end{array}$} \\
\cline { 2 - 7 } & Vo (V) & Po (W) & Eff (\%) & Vo (V) & Po (W) & Eff (\%) \\
\hline 0 & 2.25 & 6.61 & 70.51 & 2.24 & 6.61 & 69.2 \\
\hline 20 & 2.23 & 6.65 & 70.32 & 2.22 & 6.57 & 69.2 \\
\hline 40 & 2.22 & 6.59 & 70.41 & 2.21 & 6.52 & 69.1 \\
\hline 60 & 2.21 & 6.49 & 70.5 & 2.2 & 6.49 & 69.5 \\
\hline 80 & 2.17 & 6.29 & 71.4 & 2.18 & 6.38 & 69.7 \\
\hline 100 & 0 & 0 & 0 & 2.06 & 5.66 & 71 \\
\hline
\end{tabular}

A highly paralleled architecture performance is very good under extreme partial shading scenarios but with a lower power conversion efficiency. The main disadvantage for the parallel architecture is the inability of the DC-DC converter to convert small input voltages efficiently.

\section{CONCLUSIONS}

Among the three architectures discussed, the efficacy of series-parallel architecture is better in general under all operating conditions. The main drawbacks of implementing parallel architecture are the large currents generated and lack of an efficient dc-dc converter that can operate with very low input voltages. With the enhancements coming from power semiconductor devices and ability to develop efficient microconverters and inverters, parallel architectures present a potential alternative for implementing the solar arrays. An effective low-input to high output voltage converter is necessary for parallel solar array architecture to be successful. 


\section{REFERENCES}

[1] R. Coenraads, G. Reece, M. Voogt, M. Ragwitz, A. Held, G. Resch, T. Faber, R. Haas, I. Konstantinaviciute, J. Krivosík, and T. Chadim, Promotion and Growth of Renewable Energy Sources and Systems, Final Report, European Project PROGRESS, Ctrc. No. TREN/D1/422005/S07.56988, European Commission, Utrecht, The Netherlands, 2008.

[2] J. M. Carrasco, L. G. Franquelo, J. T. Bialasiewicz, E. Galván, R. C. Portillo Guisado, Ma. Á. Martıacute;n Prats, J. I. León, and N. MorenoAlfonso, "Power-electronic systems for the grid integration of renewable energy sources: A survey," IEEE Trans. Power Electron., vol. 53, no. 4, pp. 1002-1016, Jun. 2006.

[3] Deutsche Gesellschaft für Sonnenenergie, Planning and Installing Photovoltaic Systems: A Guide for Installers, Architects, and Engineers. London:Earthscan, 2005.

[4] H. Nakayama, "Stand-alone photovoltaic generation system with combined storage using lead battery and EDLC," Power Electronics and Motion Control Conference, pp 1877-1883, 2008.

[5] R. E. Hanitsch, D. Schulz and U. Siegfried, "Shading Effects on Output Power of Grid Connected Photovoltaic Generator Systems," in Revised. Energ. Ren. : Power Engineering, pp. 93-99, Berlin Germany, 2001.

[6] FSEC, Evaluation of Shading on ASE Americas ASE-300-DGF/50 Photovoltaic Module. Oct 2006.

[7] S. Buddala, S. Vemuru, V. Devabhaktuni, "Small Signal Modeling of Diode in a Parallel Module Subjected to Partial Shading," IEEE Electro Information Technology Conference, 2013.

[8] D. W. Hart, Introduction to Power Electronics. McGraw Hill, 2010.

[9] V. Salas, A. Barrado, and A. Lazarro, "Review of the maximum power point tracking algorithms for stand-alone photovoltaic systems," Solar Energy Materials \& Solar Cells, pp 1555-1578, 2006.

TABLE III. SimUlation DATA FOR DIFFERENT CONFIGURATIONS AT FULL IRRADIANCE

\begin{tabular}{|c|c|c|}
\hline Architecture & Vin (V) & Efficiency (\%) \\
\hline $1 \times 60$ & 0.472 & 36.39 \\
\hline $4 \times 15$ & 1.236 & 47.27 \\
\hline $6 \times 10$ & 1.72 & 70.51 \\
\hline $10 \times 6$ & 2.75 & 73.45 \\
\hline $15 \times 4$ & 4.585 & 77.24 \\
\hline $60 \times 1$ & 16.31 & 93.76 \\
\hline
\end{tabular}

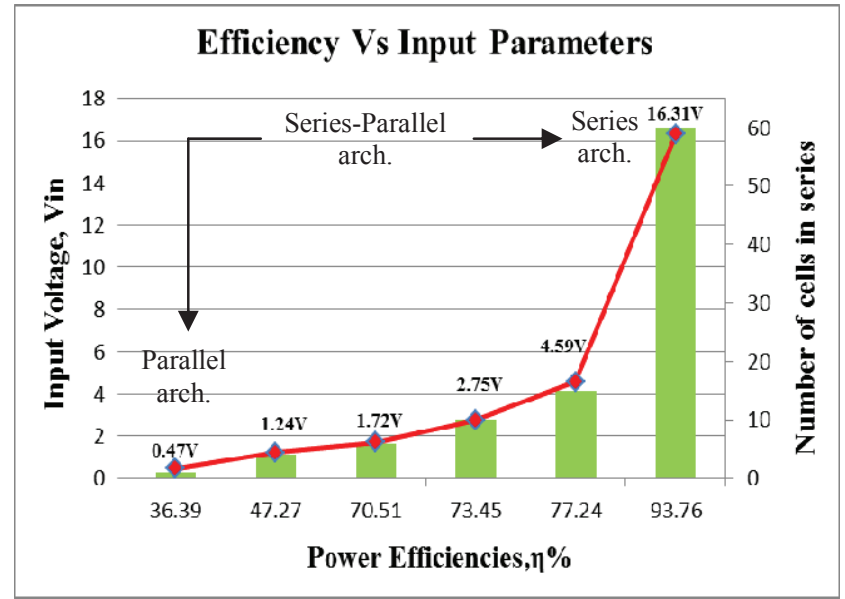

Fig. 7 Efficiency vs the input parameters for different architectures

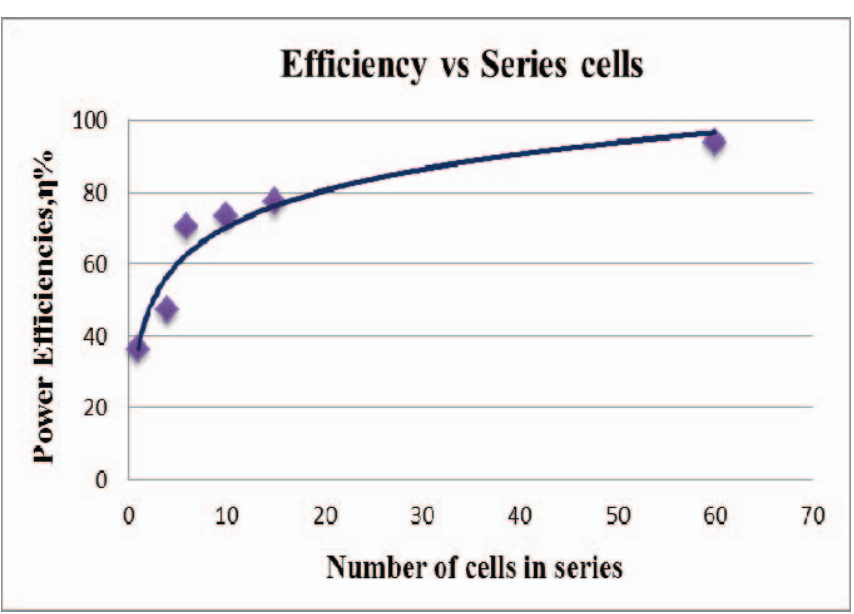

Fig. 8 Efficiency vs the number of cells in series for S-P architectures 